\section{DRT/***: Programs to administer and score the Diagnostic Rhyme Test}

\section{RANDALL J. CALISTRI and HOWARD J. KALLMAN State University of New York at Albany, Albany, New York}

The Diagnostic Rhyme Test (DRT; Voiers, 1977, 1983) was developed to measure the intelligibility of processed speech. In addition to an overall intelligibility rating, the DRT provides measures of the degree to which various distinctive features (Jakobson, Fant, \& Halle, 1963; Miller $\&$ Nicely, 1955) are intelligible after signal processing. For the test, a master list of words is recorded (or obtained from a commercial source) and then processed by one or more speech processors. During testing, the subject listens to the words over headphones and, for each word, selects which of two displayed alternatives he or she thinks was actually presented. The two displayed words rhyme and differ in terms of a distinctive feature. To the extent that the listener can reliably choose the correct alternative, evidence is provided that the relevant distinctive feature is intelligible in the speech sample (see Voiers, 1977, 1983, for details). Although the test typically employs isolated words, Schmidt-Nielsen (1983) developed a variant that allows for the testing of vowelconsonant-vowel segments that have been excised from connected speech. In addition to its use in evaluating processed speech (e.g., Allen, Strong, \& Palmer, 1981; Sandy, 1982; Smith, 1969; Voiers, 1977, 1983), the DRT has been used to study hemispheric laterality effects (Kallman, Davidson, \& Joyce, 1986) and the contribution of visual cues to speech perception (Voiers, 1973).

We have developed a package of programs that administers and scores the DRT. The programs are written in Commodore BASIC Version 2 and have been tested on the Commodore 64. Implementations of the DRT that run on other machines have been described elsewhere (Meister, 1978; Tardelli, Walter, Kennedy, \& Sims, 1985).

Word List Manipulation. The first programDRT/SET - allows the experimenter to input and/or modify to-be-tested word lists (the lists themselves may be generated using the procedures described by Voiers, $1977,1983)$. This menu-driven program initially asks the experimenter to enter two words for each trial and to specify which distinctive feature each pair of words is designed to test. During the second phase, the program asks the experimenter to indicate which of the two words

This work was supported by a grant from the General Electric Company to Howard J. Kallman. We thank General Electric for its support and the reviewers of this article for their helpful comments. Correspondence should be addressed to Howard J. Kallman, Department of Psychology, 1400 Washington Ave., Albany, NY 12222. of each trial will be the target. Other options in DRT/SET are designed to perform various housekeeping tasks such as correcting errors made during initial entry of a word list, printing or examining already entered word lists, and printing or examining the results of already performed data analyses. The word lists generated using DRT/SET are stored onto disk as sequential files and later used by a second program-DRT/EXP-to control testing.

Administration of the DRT. During testing, the subject listens to a list of words (usually recorded on a tape recorder) and after hearing each word, must choose which of two visually presented words was heard. The subject's task is to indicate, by pressing one of two experimenterspecified keys on the computer keyboard, which word he or she thinks was heard. The response is stored in memory according to whether it was correct or not. The subject may change a response by pressing a specified key, up to the time that he or she responds to the next word pair. After an experimental session is completed, a list specifying the correct and incorrect responses is stored to disk as a sequential file.

Because a response to the current word pair is required before the computer will display the next pair, it is essential that subjects be instructed to keep up and respond on every trial. With minimal practice, subjects have little trouble with this task when presentation rates are as high as approximately one word every $1.3 \mathrm{sec}$. The one source of difficulty with unpracticed subjects is with the change-response option. With fast presentation rates and unpracticed subjects, this option should not be used.

Data Analysis. A third program-DRT/ANLanalyzes the subjects' responses. This program offers three options. The first operates on the data file created by DRT/EXP and calculates the DRT scores for each list. Percentages correct are calculated according to the formula (number correct - number wrong)/total number of trials (see Voiers, 1977). Scores are calculated for each distinctive feature and for additional filler items. The scores are further broken down according to whether each distinctive feature was present or absent. Finally, an overall DRT score, which is an average of mean performance on the six tested distinctive features, is calculated.

Once the data from a number of sessions are analyzed, a second option in DRT/ANL calculates means and standard errors of the means across sessions. This option may be used to collapse the data across several subjects' or a single subject's replications. Option 2 is recursive in that output from this option may later serve as input. In such a case, Option 2 operates on the mean scores and disregards the standard errors contained in the input files; the resulting standard errors of the means are based only on the variability in the newly calculated mean scores.

In certain instances, an experimenter may be interested in performance on specific word pairs rather than in collapsing the data by distinctive feature. The third option 
of DRT/ANL accommodates this need. This option uses the raw data files generated by DRT/EXP as input. Given a number of such files, the number of correct responses for each trial is calculated. Thus, if the experimenter wishes to examine performance across sessions on, for example, the third and tenth words of a list, this option may be used.

Additional Considerations. Voiers (1977) provided information on administering the DRT. To the extent that the DRT is to be used as a standardized test for evaluating voice processing systems, rigorous listener screening and training procedures should be followed. However, when the DRT is used for other research or for clinical purposes (see Voiers, 1977, for discussion of potential clinical applications), some of the listener screening and training procedures may not be appropriate.

Availability. Listings of the DRT/*** programs may be obtained from the second author at no charge. A disk (Commodore 1541 format) that includes the programs in both interpreted and compiled BASIC may be obtained for $\$ 5$ to cover expenses.

\section{REFERENCES}

Allen, D. R., Strong, W. J., \& Palmer, E. P. (1981). Experiments on the intelligibility of low-frequency speech. Journal of the Acoustical Society of America, 70, 1248-1255.

Jakobson, R., Fant, C. G. M., \& Halle, M. (1963). Preliminaries to speech analysis: The distinctive features and their correlates. Cambridge, MA: MIT Press.
Kallman, H. J., Davidson, D., \& Joyce, E. E. (1986). A monaural right-ear advantage in perception of the graveness feature. Unpublished manuscript.

MeISTER, S. (1978). The Diagnostic Rhyme Test (DRT): An Air Force implementation (Report No. RADC-TR-78-129). Hascom Air Force Base, MA: Rome Air Development Center.

Miller, G. A., \& NiCELY, P. (1955). An analysis of perceptual confusions among some English consonants. Journal of the Acoustical Society of America, 27, 338-352.

SANDY, G. F. (1982). "Digital Voice Processor Consortium Interim Report," Appendix A (Report No. MTR-81W0159-02). McLean, VA: Mitre Corp.

SCHMIDT-NiELSEN, A. (1983). Intelligibility of VCV segments excised from connected speech. Journal of the Acoustical Society of America, 74, 726-738.

SMith, C. P. (1969). Perception of vocoder speech processed by pattern matching. Journal of the Acoustical Society of America, 46, 1562-1571.

Tardelli, J. D., Walter, C. M., Kennedy, J. W., \& Sims, J. T. (1985). Research and development for digital voice processing (Report No. RADC-TR-85-46). Hascom Air Force Base, MA: Rome Air Development Center.

VoIERS, W. D. (1973). Experimental investigation of the consonant information structure of the visible speech signal. Proceedings of the Symposium: intelligibilite de la parole-speech intelligibility, Liege, 325-334

VoIERS, W. D. (1977). Diagnostic evaluation of speech intelligibility. In M. E. Hawley (Ed.), Speech intelligibility and speaker recognition (pp. 374-387). Stroudsburg, PA: Dowden, Hutchinson, \& Ross.

Volers, W. D. (1983). Evaluating processed speech using the Diagnostic Rhyme Test. Speech Technology, 3, 30-39.

(Revision accepted for publication January 16, 1986.) 